\title{
Establishment of Cytokines Quantitative PCR Methods and Its Application in Anaphylaxis Study of Houttuynia Cordata Injection
}

\author{
Xiangqi Zeng1, Fengjiao Sun², Xiaolu Cheng1, Wen Zeng ${ }^{3}$, Li Li ${ }^{4}$ \\ ${ }^{1}$ Leshan Vocational and Technical College, Leshan, China \\ ${ }^{2}$ Key Laboratory of Animal Disease and Human Health of Sichuan Province, College of Veterinary Medicine, \\ Sichuan Agricultural University, Ya'an, China \\ ${ }^{3}$ Sichuan Primed Shines Biotech Co., Ltd., National Experimental Macaque Reproduce Laboratory, Ya'an, China \\ ${ }^{4}$ Leshan Hospital of Traditional Chinese Medicine, Leshan, China \\ Email: zengxiangqi@sina.com, 18187945@qq.com
}

Received 21 April 2015; accepted 19 June 2015; published 24 June 2015

Copyright (C) 2015 by authors and Scientific Research Publishing Inc.

This work is licensed under the Creative Commons Attribution International License (CC BY). http://creativecommons.org/licenses/by/4.0/

(c) (i) Open Access

\begin{abstract}
We design specific primers, according to the four kinds of important macaque cytokines, based on macaque $\beta$-action genes, then extract total RNA in peripheral blood mononuclear cells of macaques, and trascriptase cDNA reversely after establishing real-time quantitative PCR, and test the relative expression amount of several kinds of important cytokines during the hypersensitive process. The testing method of quantitative PCR in this experiment is highly sensitive, all cytokines are up to 102 copies/ $\mu \mathrm{L}$ and highly reproducible, the intraassay and interassay coefficients of variation are less than $6 \%$. The method applied to the sensitive reaction experiment on cytokines induced by houttuynia cordata turns out that the cytokines relative expression of houttuynia cordata distillate with low dose group and high dose group is significantly higher than that of saline group ( $P>0.01$ ). Meanwhile, significantly increased IL-4, IL-10 and IL-13 and decreased IFN- $\gamma$ are found in both group $A$ and group $B$ after houttuynia injection $(P>0.05)$.
\end{abstract}

\section{Keywords}

Cytokines, Quantitative PCR, Anaphylaxis, Houttuynia Cordata Injection

\section{Introduction}

The test methods of cytokines include ELISA [1], Elispot [2] and intracellular staining, etc. at the albumen level, which need large amount of samples and have drawbacks such as inconsistency and less sensitivity. Quantitative PCR is a nucleic acid detection and quantification technique developed in recent years, and has been applied to 
all kinds of cytokines tests. Feng et al. applied the method of quantitative PCR to test IL-8, IL-10, IFT- $\alpha$, and TNF- $\alpha$. While, Yago et al. applied the same method to determine IL-4, IL-10, TNF- $\beta$ and IFN- $\gamma$ which has characteristics such as strong specificity, high sensitivity, good repeatability, and accurate quantitation. It is infrequently reported that this method is applied to cytokines determination in body fluids of macaques, an important species of experimental animals, and drug evaluation.

Houttuynia cordata is a traditional Chinese medicine preparation for detoxification and immunity enhancement. In recent years, Houttuynia injection has been reported to cause many allergic reactions in clinical application. The present study finds that the main anaphylactogen is the solubilizer, Tween-80, which is used in injection. IFN- $\gamma$, IL-4, IL-10 and IL-13 have close relationship with the immune response. IL-4 and IL-13 have the function of promoting production of IgE [3] [4]. The anatomical structure and the physiological characteristics of macaques are similar to those of humans. Thus they are usually chosen as models in studying human diseases. In this trial, Chinese origin rhesus monkeys are selected as experimental animals. We aim to establish the testing method of quantitative PCR for the cytokines related to non-human primate experimental animals, and test the level of IL-4, IL-10, IL-13 and IFN- $\gamma$ in cytokines related to the body immune of macaques after houttuynia injection and distilled water injection.

\section{Material and Method}

\subsection{Experimental Animals}

15 macaques, weight 4 - $6 \mathrm{~kg}$, all males, were provided by the experimental animal center of Engineering Technology in Sichuan Agricultural University.

\subsection{Instruments and Reagents}

CFX96 Touch Deep Well ${ }^{\text {TM }}$ Real-Time PCR Detection System(BIO-RAD company in USA), $0.2 \mathrm{ml}$ eight tube purchased from Dien biological technology (Hongkong) Co., Ltd., Houttuynia cordata injection (containing 2.5 per thousand Tween-80, the batch number, the country medicine accurate Z44021272), Houttuynia cordata distillate (the batch number, 130330), Egg protein (dry powder) (sigma company, the batch number: 44287), Tween-80 (the batch number: 20111102), human lymphocyte separation medium(the batch number: 20121009-0028), RNA extraction kit, RNA reverse transcription kit and SYBR-Green II quantitative detection kit were purchased from Dalian Takara Biotechnology Co., Ltd.

\subsection{Design and Synthesis for Primers}

According to the mRNA sequence of various cytokines monkeys in GenBank login, primer design software Primer 5.0 and BLAST software are designed for specific reference gene amplification primers and cytokine PCR specific amplification primers (shown in Table 1). Primers were synthesized by Dalian Takara biotechnology company.

\subsection{Design for Animal Experiment}

Animal grouping: Divide macaques into 5 groups randomly $(\mathrm{n}=3$ ), which are Group A (with 2.5 g/L Tween-80), the physiological saline group and herba Houttuynia injection, Group B (with 5 g/L Tween-80), Houttuynia cordata injection, the low dose group $(3.6 \mathrm{ml} / \mathrm{kg})$ for Houttuynia cordata distillate and the high dose group $(7.2 \mathrm{ml} / \mathrm{kg}$ ) for Houttuynia cordata distillation liquid.

Dosage: Macaques in each group were given the corresponding liquid on the 1st, 3nd, 5th, 7th, 9th, 20th day. The first 5 times are the sensitive periods. The Volume of administration: Group A and B of Houttuynia cordata injection, saline group, low dose group of Houttuynia cordata distillation liquid $3.6 \mathrm{ml} / \mathrm{kg}$ (The amount of group A and Group B of Houttuynia injection is equivalent to 2.5 times the clinical adult dosage); High dose group of Houttuynia distillate $7.2 \mathrm{ml} / \mathrm{kg}$, the 6th excitation administration, the dosing volume: Group A and B of Houttuynia cordata injection, saline group, low dose group of Houttuynia cordata distillation liquid $7.2 \mathrm{ml} / \mathrm{kg}$. (The amount of group A and Group B of Houttuynia injection is equivalent to 5 times the clinical adult dosage). The high dose group of Houttuynia cordata distillate is administered with volume $14.4 \mathrm{ml} / \mathrm{kg}$. Samples were collected from the vein $30 \mathrm{~min}$ after the last dose. 
Table 1. Real-time PCR primers.

\begin{tabular}{|c|c|c|c|c|}
\hline Gene & Accession & Primer sequences & Location & Length \\
\hline \multirow[t]{2}{*}{$\beta$-actin } & AY497558 & F5’GGCTCTCTTCСААССТТССТТЗ’ & $613-634$ & 176 bp \\
\hline & & F5’TАATCTCСТTCTGCATCСТGTCA3’ & $765-788$ & \\
\hline \multirow[t]{2}{*}{ IL-4 } & NM001032904 & F5' CTGAACAGCCTCACAGAGCAGAAGA3’ & $112-127$ & 136 bp \\
\hline & & F5’ GGTGGCTGTAGAACTGCCGGAG 3’ & $225-247$ & \\
\hline \multirow[t]{2}{*}{ IL-10 } & NM001044727 & F5’ GGAGCAGGTGAAGAATGCCTTTAGT3’ & $424-449$ & 104 bp \\
\hline & & F5’ TTGTCATGTAGGCTTCTATGTAGTTG3’ & $502-527$ & \\
\hline \multirow[t]{2}{*}{ IL-13 } & NM001032929 & F5’ CTTTGCCTCCССAAGCССТGT3’ & $48-70$ & 87 bp \\
\hline & & F5’GCCTTCTGGTTCTGGGTGATGTTG3’ & $110-134$ & \\
\hline \multirow[t]{2}{*}{ IFN- $\gamma$} & MACIFNG & F5'GGAAAGAGGAGAGTGACAGAAAAAT 3' & $176-201$ & $121 \mathrm{bp}$ \\
\hline & & F5’ TCTTCCTTGATGGTCTCCACACTC 3’ & $272-296$ & \\
\hline
\end{tabular}

Ethics statement: All procedures were reviewed and approved by the Institutional Animal Care and Use Committee (IACUC) of Sichuan Primed Shines Biotech Co., Ltd.

\subsection{The Establishment of Real-Time Quantitative PCR Testing Methods of Cytokines}

Lymphocyte separation: Put $0.6 \mathrm{ml}$ fresh anticoagulant blood lightly into $1.2 \mathrm{ml}$ lymphocyte separation medium (to warm up in advance, $1500 \mathrm{r} / \mathrm{min}, 15 \mathrm{~min}$ ). Learn the second layers of annular milky white lymphocyte layer in a $1.5 \mathrm{ml}$ EP tube, add appropriate amount of PBS for washing, then $5000 \mathrm{r} / \mathrm{min}$ centrifugal $5 \mathrm{~min}$, discard supernatant and collect precipitation, add PBS for suspension.

Extraction of total RNA: Take out $50 \mu 1$ lymphocytes, and use RNAiso Plusfrom Bao biotechnology company to Extract RNA according to the instruction. Analyze the integrity of RNA with $1 \%$ formaldehyde denaturing agarose gel electrophoresis, and store in $-70^{\circ} \mathrm{C}$ for standby.

The synthesis of cDNA: Due to the high sensitivity of real-time quantitative PCR method, we need to conduct genome removal reaction according to the instruction. After that, the reaction mixture was prepared on ice. Sequentially added $4 \mu \mathrm{l} 5 \times$ PrimerScript Buffer $2.1 \mu \mathrm{l}$ PrimerScript RT Enzyme Mix 1.1 $\mu \mathrm{l}$ RT Primer Mix, $10 \mu \mathrm{l}$ reaction liquid for removing genome, place the sample in $37^{\circ} \mathrm{C}$ for $15 \mathrm{mins}$, heat i to $85^{\circ} \mathrm{C}$, and suspend after 5 seconds, then obtain cDNA to store for standby.

Construction of the standard curve of macaque cytokines: Use specific primers IL-4, IL-10, IL-13, IFN- $\gamma$ and reference gene $\beta$-actin for amplification. The recovered fragment is connected to the pMD-19T vector and transformed to DH5 $\alpha$ competent cells. Recombine the plasmid to indentify by PCR and sequencing. Convert the corect initial concentration of a recombinant plasmid into copy data. 10-fold dilutions to get 108 copies/ $\mu \mathrm{l}-101$ copies/ $\mu$ l gradient standard.

Optimization of the reaction system: In the reaction system template of the same concentration, use orthogonal test primer concentrations respectively and optimize the annealing temperature.

Specificity test: 10 -fold serial dilutions of plasmid standards as a template, use the optimized reaction conditions to amplify the fluorescence quantitative PCR and plot the melting curve.

Standard curve: 10 -fold serial dilutions of plasmid standards as a template, use the optimized reaction conditions to amplify the fluorescence quantitative PCR, and draw a standard curve.

Sensitivity test: Plasmid standard ( $\beta$-actin: 103 copies/ $\mu l-101$ copies/ $\mu l$, the remaining factors are using 104 copies $/ \mu \mathrm{l}-101$ copies $/ \mu \mathrm{l}$ ) as a template, use the optimized reaction conditions SYBR Green II to amplify the fluorescence quantitative PCR, and determine their the detection limit.

Repeatability test: Select 106 copies/ $\mu 1$ - 104 copies/ $\mu 1$ recombinant plasmid as a template for intra- and interassay repeated tests, each test has three times to repeat testing of Ct values of the concentration of the standard statistical analysis.

The use of quantitative PCR for IL-4, IL-10, IL-13 and IFN- $\gamma$ mRNA levels were detected, the test results were analyzed utilizing SPSS 16.0. 


\section{Results}

\subsection{Preparation of Primers and Identification of Standard Product}

PCR amplify $\beta$-actin, IL-4, IL-10, IL-13 and IFN- $\gamma$ to obtain the product which have the same size as the fragment and non-specific amplification product. After the producrion is recoved, and is cloned into the pMD-19T vector, identified by PCR and sequencing, which is proved that this experiment designed primers can be specifically amplified fragment.

\subsection{Optimization of the Reaction System}

According to the results of kinetic curves and amplify efficiency determination optimization, the final reaction system ( $25 \mu \mathrm{l})$ is SYBR Green II Mix $12.5 \mu \mathrm{l}$, the downstream primer (4 pmol/ $\mu \mathrm{l})$ each $1 \mu \mathrm{l}$ and template $2 \mu \mathrm{l}$, $\mathrm{H} 2 \mathrm{O} 9.5 \mu \mathrm{l}$. The best response procedures are $94^{\circ} \mathrm{C} 5 \mathrm{~min}, 94^{\circ} \mathrm{C} 20 \mathrm{~s}, 59.8^{\circ} \mathrm{C} 30 \mathrm{~s}, 95^{\circ} \mathrm{C} 10 \mathrm{~s}$ and $72^{\circ} \mathrm{C} 10 \mathrm{~s}$.

\subsection{Specific Detection}

Quantitative PCR results showed that, $\beta$-actin, IL-4, IL-10, IL-13 and IFN- $\gamma$ have a single melting peak (Figure 1), indicating that this method has good specificity.

\subsection{Establishing the Standard Curve}

Amplify quantitative PCR to obtain the standard curve (Figure 2) of $\beta$-actin, IL-4, IL-10, IL-13 and IFN- $\gamma$, which shows the initial template concentration and $\mathrm{Ct}$ value of the standard showed good linearity relationship, $\beta$-actin standard curve equation is as follows: $\mathrm{y}=-3.487 \mathrm{x}+40.118$, the correlation coefficient R2 at 0.999, IL-4 standard curve equation is as follows: $y=-3.619 x+30.623$, the correlation coefficient R2 at 0.993 , IL-10 standard curve equation is as follows: $y=-3.579 x+38.423$, the correlation coefficient R2 at 0.996, IL-13 standard curve equation is as follows: $\mathrm{y}=-3.388 \mathrm{x}+35.380$, the correlation coefficient $\mathrm{R} 2$ in 0.995 , IFN- $\gamma$ calibration curve equation is as follows: $\mathrm{y}=-3.709 \mathrm{x}+40.094$, the $\mathrm{R} 2$ correlation coefficient 0.996 .

\subsection{Sensitivity Analysis}

The detection limit of $\beta$-actin, IL-4, IL-10, IL-13 and IFN- $\gamma$ is $8.76 * 102$ copies/ $\mu$ (Figure 3), which indicates that this method has good sensitivity.

\subsection{Repeatability Analysis}

Use three concentrations of plasmids to amplify the fluorescent quantitative PCR, each concentration in triplicate (Figure 4). The results prove that the results of this experiment can be repeated within the $\beta$-actin Ct value

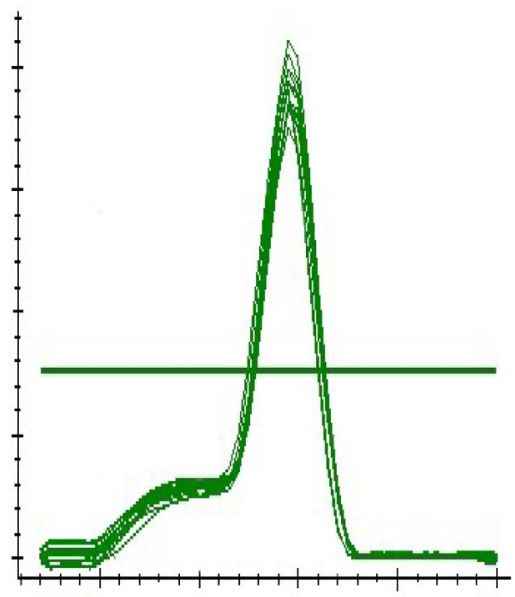

$\mathbf{T} /{ }^{\circ} \mathbf{C}$

Figure 1. The melt curve of RT-PCR. 


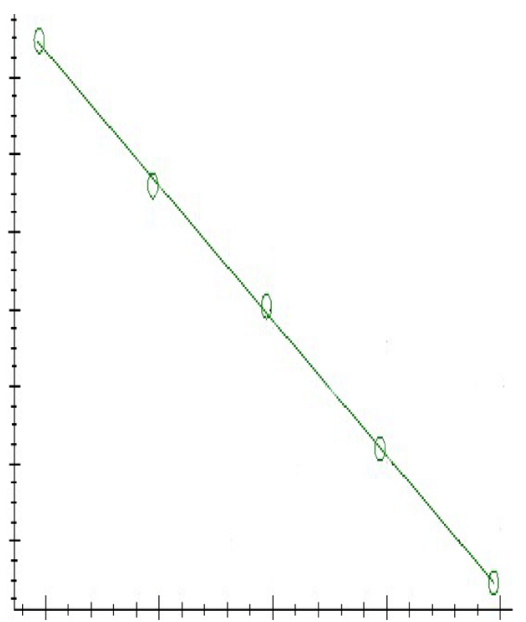

Concentration of template $(\log$ MR)

Figure 2. Amplification curve and standard curves.

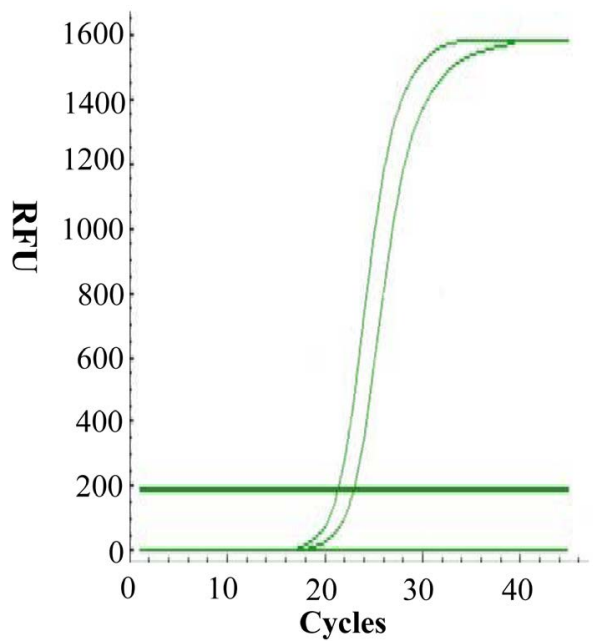

Figure 3. Sensitivities of real-time PCR detection.

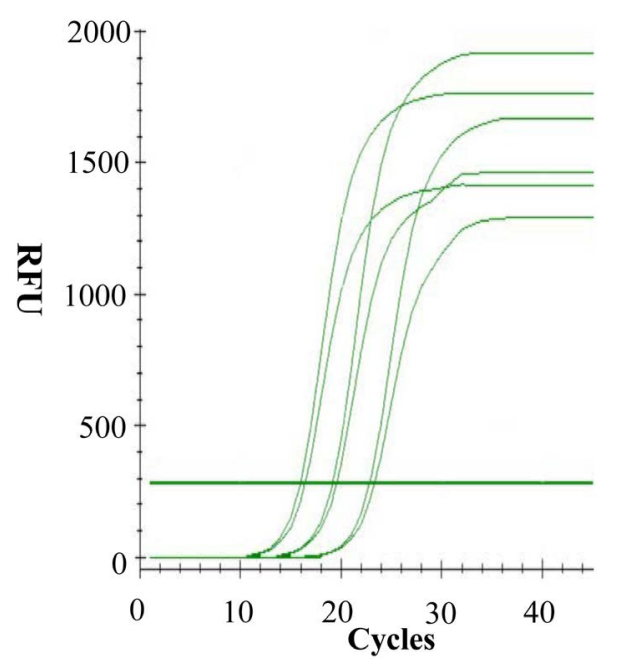

Figure 4. The reproducibility of rRT-PCR. 
of the coefficient of variation $<0.02$, and inter-assay coefficients of variation between $0.018-0.060$, within the IL-4 Ct value coefficient of variation $<0.04$, and inter-assay coefficients of variation between between 0.032 0.042 , within the IL-10 Ct value coefficient of variation $<0.04$, and inter-assay coefficients of variation between $0.039-0.057$, within the IL-13 Ct value coefficient of variation $<0.02$, and inter-assay coefficients of variation ranged between $0.017-0.026$, IFN $-\gamma$ Ct value within assay coefficient of variation $<0.02$, and inter-assay coefficients of variation between $0.018-0.062$.

\subsection{Sample Test Results}

Using real-time quantitative PCR method to establish four kinds of macaques in vivo cytokine mRNA expression quantitative detection, Get the copy number of each group macaques $\mathrm{Ct}$ values and initial template. Samples were analyzed using statistical analysis software cytokine mRNA quantitative test results. With the number of copies of the measured cytokines in each group (average of multiple measurements obtained) divided by the number of $\beta$-actin gene (the average of multiple measurements obtained) copy, as a correction value. The correction value as a negative control group " 1 ", the calculated IL-4, IL-10, IL-13 and IFN- $\gamma$ relative expression of cytokines, and then comparison of the relative amounts of the groups, four kinds of cytokines differences between different groups in the analysis of results shown in Figure 5. The results showed that: Houttuynia distillate low dose group and high dose group compared to the expression of IFN- $\gamma$ mRNA negative control group were significantly higher $(\mathrm{P}<0.01)$ in, and Houttuynia injection in group A and group B is slightly lower. Compared with the negative control group was significantly higher distillate Houttuynia low dose group and high dose group expression levels of IL-13 ( $\mathrm{P}<0.01$ ), while in group A and Houttuynia injection is not significantly increased in group $B(P>0.05)$. Houttuynia distillate low dose group and high dose group relative to the negative control group of cytokines IL-4 mRNA expression levels were significantly increased $(\mathrm{P}<0.01)$, while Houttuynia injection group A and group B relative to the negative control group increased slightly, but not significantly ( $\mathrm{P}>0.05)$. For IL-10, Houttuynia distillate low dose group and high dose group were significantly higher than the negative control group $(\mathrm{P}<0.01)$. Houttuynia injection in group A and group B IL-10 mRNA expression were higher than the negative control group, but the difference was not significant $(\mathrm{P}>0.05)$.
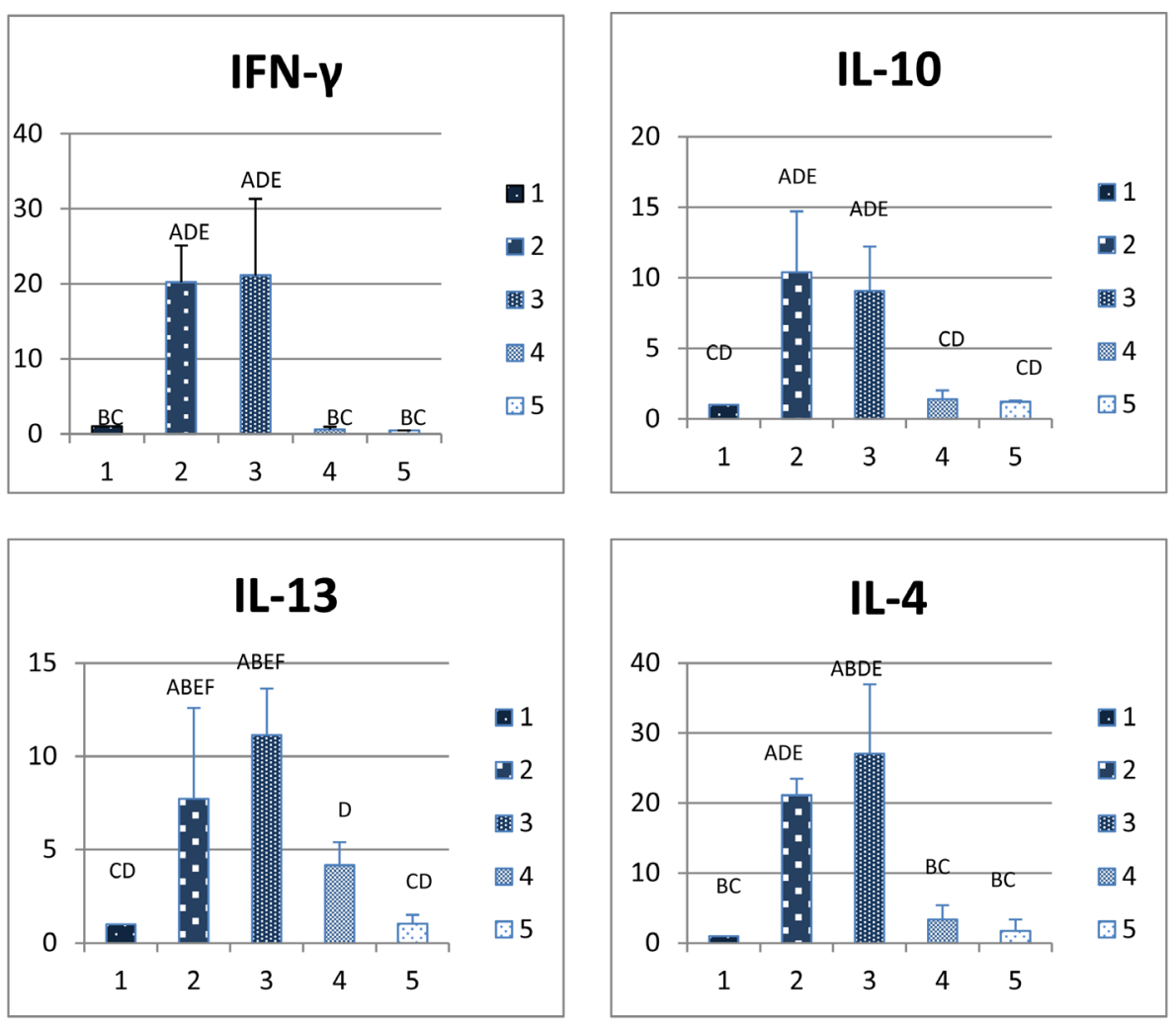

Figure 5. Analysis of IL-4, IL-10, IL-13 and IFN- $\gamma$ mRNA from rhesus monkeys among different groups. 


\section{Discussion}

In recent years, real-time PCR has become an important tool widely used in basic research and quantitatively analyzing the level of cells, body fluids and bioactive protein mRNA in clinical diagnosis [5]. The results showed that the linear method established in this test is good, with the correlation coefficient (R2) reached 0.999, and a detection limit of $8.76 * 102$, with better sensitivity, quantitative PCR product into a single melting peak, with good specificity, between the experimental group and the group within the repeatability coefficient of variation were less than $2 \%$, with good reproducibility.

The method established in this experiment was used to test the relative expression of IFN- $\gamma$, IL-4, IL-10, and IL-13 mRNA in each group. The results showed that different concentrations of two macaques Houttuynia distillate vivo IFN- $\gamma$ mRNA expression levels were significantly increased, which show that Houttuynia can enhance immunity, which is consistent with the thought of Gu Jingrong [6] [7]. Compared with Houttuynia injection group containing different concentrations of Tween-80, Houttuynia injection group A and group B in macaques vivo IFN- $\gamma$ did not change significantly. Houttuynia injection group A and group B, the expression level of IL-4, IL-13 mRNA was increased, which is associated with the research result of allergic rhinitis [8] and allergic asthma [9]. The expression levelof IL-10 mRNA is also elevated, which matches the findings of Wong, et al. [10].

\section{Conclusion}

In summary, the established quantitative PCR method can be used in real-time monitoring of mRNA levels of cytokines in injecting the rhesus monkeys. After injecting the rhesus monkeys Houttuynia to test the cell-mediated immunity levels and the allergic reactions, the methods can test the expression levels of IL-4, IL-10, IL-13 and IFN- $\gamma$ mRNA quickly and accurately. When the body's immune is enhanced and occurs the allergic reaction IL-4, IL-10, IL-13 and IFN- $\gamma$ were involved in it. In the research of the allergic mechanism, several cytokines are used as indexes, and this experiment provides the new reference factors for allergic reactions and lays the foundation for future studies and allergic mechanisms.

\section{References}

[1] Varin, A., Mukhopadhyay, S., Herbein, G. and Gordon, S. (2010) Alternative Activation of Macrophages by IL-4 Impairs Phagocytosis of Pathogens but Potentiates Microbial-Induced Signaling and Cytokine Secretion. Blood, 115, 353362. http://dx.doi.org/10.1182/blood-2009-08-236711

[2] Kai, F., Justine, T., Bernhard, O., Lehmann, P.O. and Tary-Lehmann, M. (2010) Th1 Responses to Beta-Amploid in Young Humans Convert to Regulatory IL-10 Responses in Down Syndrome and Alzheimer's Disease. Neurobiology of Aging, 31, 1732-1742. http://dx.doi.org/10.1016/j.neurobiolaging.2008.09.007

[3] Yang, M., Cheng, A.C., Wang, M.S. and Xing, H.Y. (2008) Development and Application of One-Step Real-Time Taqman RT-PCR Assay for Detection of Duck Hepatitis Virus Type1. Journal of Virological Methods, 153, 55-60. http://dx.doi.org/10.1016/j.jviromet.2008.06.012

[4] de Coaña, Y.P., Barrero, C., Cajiao, I., Mosquera, C., Patarroyo, M.E. and Patarroyo, M.A. (2004) Quantifying Aotus Monkey Cytokines by Real-Time Quantitative RT-PCR. Cytokine, 27, 129-133. http://dx.doi.org/10.1016/j.cyto.2004.04.004

[5] Stordeur, P., Poulin, L., Craciun, L., Zhou, L., Schandené, L., de Lavareille, A., et al. (2002) Cytokine mRNA Quantification by Real-Time PCR. Journal of Immunological Method, 259, 552-641. http://dx.doi.org/10.1016/s0022-1759(01)00489-6

[6] Giulietti, A., Overbergh, L., Valckx, D., Brigitte Decallonne, B., Roger Bouillon, R. and Chantal Mathieu, C. (2001) An Overview of Real-Time Quantitative PCR: Applications to Quantify Cytokines Gene Expression. Methods, 25, 386-401. http://dx.doi.org/10.1006/meth.2001.1261

[7] Rudge, E.U., Cutler, A.J., Pritchard, N.R. and Smith, K.G.C. (2002) Interleukin 4 Reduces Expression of Inhibitory receptors on B Cells and Abolishes CD22 and Fc $\gamma$ RII-Mediated B Cell Suppression. The Journal of Experimental Medicine, 195, 1079-1085. http://dx.doi.org/10.1084/jem.20011435

[8] Pawakar, R., Okuda, M., Yssel, H., Okumura, K. and Ra, C. (1997) Nasal Mast cells in Perennial Allergic Rhinitics Exhibit Increased Expression of the FceRI, CD40L, IL-4, and IL-13, and Can Induce IgE Synthesis in B Cells. Journal of Clinical Investigation, 99, 1492-1499. http://dx.doi.org/10.1172/JCI119311

[9] Wills-Karp, M., Luyimbazi, J., Xu, X.Y., Schofield, B., Neben, T.Y., Karp, C.L., et al. (1998) Interlukin-13: Central 
Mediator of Allergic Asthma. Science, 282, 2258-2261. http://dx.doi.org/10.1126/science.282.5397.2258

[10] Wong, C.K., Ho, C.Y. Ko, W.S., Chan, C.H.S., Ho, A.S.S. Hui, D.S.C. and Lam, C.W.K. (2001) Proinflammatory Cytokines (IL-17, IL-6, IL-18 and IL-12) and Th Cytokines (IFN- $\gamma$, IL-4, IL-10 and IL-13) in Patients with Allergic Asthma. Clinical and Experimental Immunology, 125, 177-183. http://dx.doi.org/10.1046/j.1365-2249.2001.01602.x 